\title{
Role of cancer antigen-125 in diagnosing malignant adnexal masses: a prospective observational study
}

\author{
Shazia Ashraf Khan*, Shaista Rahi1, Nahida Khan
}

\begin{abstract}
Department of Obstetrics and Gynaecology, Lala Ded Hospital, Government Medical College, Srinagar, Jammu and
\end{abstract} Kashmir, India

Received: 17 July 2020

Revised: 21 August 2020

Accepted: 03 September 2020

\section{*Correspondence:}

Dr. Shazia Ashraf Khan,

E-mail: shaziashrafkhan@rediffmail.com

Copyright: (C) the author(s), publisher and licensee Medip Academy. This is an open-access article distributed under the terms of the Creative Commons Attribution Non-Commercial License, which permits unrestricted non-commercial use, distribution, and reproduction in any medium, provided the original work is properly cited.

\section{ABSTRACT}

Background: Adnexal masses present a diagnostic and therapeutic dilemma across age-groups. This study aimed to evaluate the performance of cancer antigen-125 (CA-125) in distinguishing between benign and malignant adnexal masses.

Methods: This was a prospective, observational, single tertiary-care center study, done in North India from January, 2011 till December, 2012. Serum CA-125 levels was obtained preoperatively in consecutive patients presenting with ultrasonography confirmed adnexal masses. The cut-off value between benign and malignant was taken as $35 \mathrm{IU} / \mathrm{ml}$. Histopathological diagnosis was obtained in all patients.

Results: A total of 126 patients presented with adnexal masses, of which 100 were enrolled (mean age: $37.5 \pm 14.4$ years, range: $18-80$ years). Most of the masses were benign $81 \%$ (malignant=19\%). Dermoid cyst (25.9\%) and endometriomas $(21 \%)$ were the most common benign masses. Serous $(21 \%)$ and mucinous cystadeno-carcinoma (15.8\%) were the most common malignant masses, more often seen in elderly, married, parous and post-menopausal patients. Mean CA-125 levels were significantly higher in malignant masses $(257.30$ [105.68-408.92] versus 19.26 [16.53-22.00], p<0.001). Overall sensitivity, specificity, positive predictive value, negative predictive value and accuracy of CA-125 for diagnosing malignant adnexal mass was $94.7 \%, 87.65 \%, 64.28 \%, 98.6 \%$, and $88.91 \%$ respectively. The same was $100 \%, 85.1 \%, 54.5 \%, 100 \%, 87.3 \%$ in premenopausal and $85.7 \%, 100 \%, 100 \%, 93.3 \%, 95.2 \%$ in postmenopausal women respectively.

Conclusion: Benign masses form the bulk of the adnexal masses in all age groups. CA-125 levels has high sensitivity and negative predictive value in premenopausal patients while as high specificity and positive predictive value in postmenopausal patients.

Keywords: Adnexal masses, Biomarkers, Cancer antigen -125, Ovarian malignancies,

\section{INTRODUCTION}

Adnexal masses represent a spectrum of conditions involving both gynaecological and non-gynaecological sources often presenting with diagnostic and therapeutic dilemma. ${ }^{1,2}$ Although the differential diagnosis is extensive, most of the cases represent benign processes. ${ }^{1,2}$ Most frequently, adnexal masses refer to ovarian masses or cysts; however, paratubal cysts, hydrosalpinx, and other non-ovarian masses are also included within the broader definition of adnexal masses. ${ }^{1,2}$

Various tumour markers have been used for diagnosis of ovarian/adnexal malignancies., ${ }^{3,4}$ CA-125 (carcinoma antigen 125) is the most widely studied tumour associated antigen for ovarian carcinoma. CA-125, also known as mucin 16 or metastatic urothelial carcinoma 16 (MUC-16), is a member of the mucin family glycoproteins encoded by 
the MUC-16 gene. ${ }^{3,4}$ An elevated serum CA-125 level of at least 35 units $/ \mathrm{ml}$ is often considered to indicate the presence of malignancy although other cut-off values have been used. ${ }^{3,4}$ In addition to ovarian malignancies elevated levels may also be associated with the malignancies of lung, bowel, breast and pancreas. ${ }^{3-5}$ Non-malignant pathological conditions affecting the peritoneal surface such as endometriosis, fibroids and other inflammatory conditions may also have elevated CA-125 levels. ${ }^{3-5}$ However, levels are rarely more than 100-200 IU/ml in patients with these benign conditions. ${ }^{3-5}$ Even in patients with histo-pathologically confirmed ovarian malignancies, low levels can be seen in women who have early stage invasive disease and borderline ovarian tumors. ${ }^{3-5}$ In view of these limitations and the existing lacunae in the literature, we aimed to evaluate the performance of CA125 for diagnosis of malignancy in adnexal masses in a single tertiary care center prospective observational study.

\section{METHODS}

This prospective observational study was conducted between January 2011 and December 2012 at the Department of Obstetrics and Gynecology, Government Lalla Ded Hospital associated with Government Medical College Srinagar which is a tertiary care referral center for maternity and gynecology services. Consecutive patients presenting with adnexal masses on pelvic examination or conventional ultrasound as well as cases referred to our center for evaluation of adnexal masses were enrolled. A detailed history and a thorough general and systemic examination was carried out in all patients. All the baseline investigations including hemogram, blood grouping, kidney and liver function test, chest radiograph, Electrocardiogram (ECG) were obtained in each case. The presence of adnexal masses was confirmed by ultrasonography (USG). Magnetic resonance imaging (MRI) or Computed tomography (CT) was done prior to surgery wherever indicated. Patients with unilocular anechoic small cyst (less than $5 \mathrm{~cm}$ ) which resolved on follow up ultrasound examination, tubal gestations and masses that were found to arise from uterus were excluded.

Patients with symptomatic or suspicious adnexal masses were subjected to laparotomy or laparoscopy depending upon size, complexity and other morphological characteristics of the adnexal mass. Histo-pathological diagnosis was obtained in all patients.

Serum CA-125 levels were measured in blood sample obtained from the patients preoperatively. Levels were determined by immunoassays with a monoclonal antibody. The cut-off value between benign and malignant was taken as $35 \mathrm{IU} / \mathrm{ml}$, with value of more or equal to $35 \mathrm{IU} / \mathrm{ml}$ indicating malignancy. Sensitivity, specificity, positive predictive valve and negative predictive value of CA-125 levels for the presence of a malignant adnexal mass were calculated.
Statistical data was described as mean \pm standard deviation (SD) and percentage. The inter group variance was measured at $95 \%$ confidence interval. Comparison of metric data was done by Student's t-test and Fisher's exact test whereas non-metric data was analyzed by Chi-square test and Mann-Whitney U test. Statistical package for social sciences (SPSS Version 17), java stat and microsoft excel software were used for data analysis.

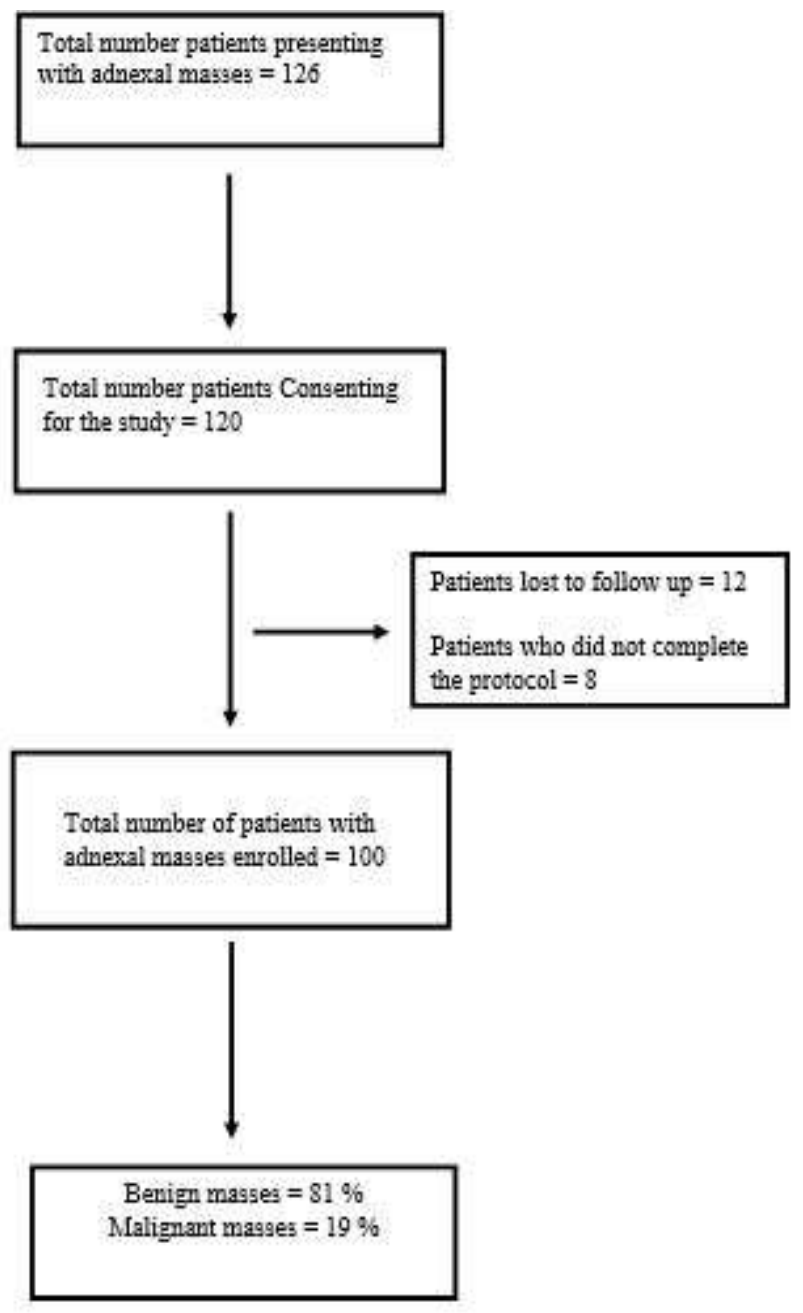

Figure 1: Methodology.

\section{RESULTS}

A total of 126 patients presented with adnexal masses during the study period. Six patients did not consent for inclusion into the study. Out of the remaining 12 patients were lost to follow up before completing the study protocol. Other 8 patients could not be enrolled either because they did not complete the diagnostic protocol or there histo-pathological diagnosis was not confirmed till the final compilation of this data. A total of 100 patients was therefore enrolled for the final analysis. Mean age of patients was 37.5 years (range 18-80 years). 
Table 1: Demographic Characteristics of all patients presenting with adnexal masses $(n=100)$.

\begin{tabular}{|llll|}
\hline \multicolumn{1}{|c}{ Characteristics } & & $\mathbf{n}$ & \multicolumn{1}{c|}{ Percentage } \\
\hline \multirow{3}{*}{ Age (years) } & $<25$ & 16 & 16.0 \\
\cline { 2 - 4 } & 25 to 49 & 61 & 61.0 \\
\cline { 2 - 4 } & $\geq 50$ & 23 & 23.0 \\
\cline { 2 - 4 } Mean \pm SD & $37.5 \pm 14.4(18-80)$ & 24.0 \\
\hline \multirow{2}{*}{ Parital status } & Unmarried & 24 & 76.0 \\
\cline { 2 - 4 } & Married & 76 & 33.0 \\
\hline \multirow{2}{*}{ Menstrual status } & Nulliparous & 33 & 67.0 \\
\cline { 2 - 4 } & Parous & 67 & 79.0 \\
\hline Significant positive family history & Pre-menopausal & 79 & 21.0 \\
\cline { 2 - 4 } & Post-menopausal & 21 & 5.0 \\
\hline
\end{tabular}

Table 2: Chief Complaints of all patients presenting with adnexal masses $(n=100)$.

\begin{tabular}{|lll|}
\hline Characteristics & n & Percentage \\
\hline Pain & 69 & 69.0 \\
\hline Menstrual irregularity & 42 & 42.0 \\
\hline Lump & 23 & 23.0 \\
\hline Infertility & 5 & 5.0 \\
\hline Postmenopausal bleeding & 4 & 4.0 \\
\hline Asymptomatic & 6 & 6.0 \\
\hline
\end{tabular}

Table 3: Histopathological Diagnosis of all adnexal masses $(n=100)$.

\begin{tabular}{|c|c|c|c|c|c|c|}
\hline \multirow{2}{*}{ Histopathological diagnosis } & \multicolumn{2}{|c|}{ Malignant (n=19) } & \multicolumn{2}{|c|}{ Benign $(\mathrm{n}=\mathbf{8 1})$} & \multicolumn{2}{|c|}{ Total } \\
\hline & $\mathbf{n}$ & $\%$ & $\mathbf{n}$ & $\%$ & $\mathbf{n}$ & $\%$ \\
\hline Serous cystadenocarcinoma & 4 & 21.05 & - & - & 4 & 4.0 \\
\hline Granulosa cell tumour & 2 & 10.5 & - & - & 2 & 2.0 \\
\hline Metastatic deposits & 2 & 10.5 & - & - & 2 & 2.0 \\
\hline Mucinous cystadenocarcinoma & 3 & 15.8 & - & - & 3 & 3.0 \\
\hline Dysgerminoma & 2 & 10.5 & - & - & 2 & 2.0 \\
\hline Papillary cystadenocarcinoma & 1 & 5.3 & - & - & 1 & 1.0 \\
\hline Papillary serous cystadenocarcinoma & 1 & 5.3 & - & - & 1 & 1.0 \\
\hline Signet cell carcinoma & 1 & 5.3 & - & - & 1 & 1.0 \\
\hline Squamous cell carcinoma of ovary & 1 & 5.3 & - & - & 1 & 1.0 \\
\hline Adenocarcinoma & 1 & 5.3 & - & - & 1 & 1.0 \\
\hline Clear cell carcinoma & 1 & 5.3 & - & - & 1 & 1.0 \\
\hline Dermoid cyst & - & - & 21 & 25.9 & 21 & 21.0 \\
\hline Endometrioma & - & - & 17 & 21.0 & 17 & 17.0 \\
\hline Serous cystadenoma & - & - & 15 & 18.5 & 15 & 15.0 \\
\hline Mucinous cystadenoma & - & - & 8 & 9.9 & 8 & 8.0 \\
\hline Haemmorhagic cyst & - & - & 5 & 6.2 & 5 & 5.0 \\
\hline Tubo-ovarian abscess & - & - & 3 & 3.7 & 3 & 3.0 \\
\hline Corpus luteal cyst & - & - & 3 & 3.7 & 3 & 3.0 \\
\hline Papillary serous cystadenofibroma & - & - & 2 & 2.5 & 2 & 2.0 \\
\hline Hydrosalpinx & - & - & 2 & 2.5 & 2 & 2.0 \\
\hline Follicular cyst & - & - & 2 & 2.5 & 2 & 2.0 \\
\hline Cystadenofibroma & - & - & 1 & 1.2 & 1 & 1.0 \\
\hline Fibroma ovary & - & - & 1 & 1.2 & 1 & 1.0 \\
\hline Sebaceous yst & - & - & 1 & 1.2 & 1 & 1.0 \\
\hline Total & 19 & 19.0 & 81 & 81.0 & 100 & 100.0 \\
\hline
\end{tabular}


Table 4: Histopathology with demographic variables of patients with adnexal masses (n=100).

\begin{tabular}{|llllll|}
\hline \multicolumn{1}{|c}{ Characteristics } & \multicolumn{2}{c}{ Malignant } & \multicolumn{3}{c|}{ Benign } \\
\hline \multirow{3}{*}{ Age (years) } & & n & \% & n & \% \\
& $<25$ & 1 & 6.3 & 15 & 93.8 \\
\cline { 2 - 6 } & 25 to 49 & 11 & 18.0 & 50 & 82.0 \\
\cline { 2 - 6 } & $\geq 50$ & 7 & 30.4 & 16 & 69.6 \\
\hline \multirow{2}{*}{ Marital Status } & Unmarried & 3 & 12.5 & 21 & 87.5 \\
\cline { 2 - 6 } Parity & Married & 16 & 21.1 & 60 & 78.9 \\
\hline \multirow{2}{*}{ Menstrual Status } & Nulliparous & 4 & 12.1 & 29 & 87.9 \\
\cline { 2 - 6 } & Parous & 15 & 22.4 & 52 & 77.6 \\
\hline \multirow{2}{*}{ Family History } & Pre-menopausal & 13 & 16.5 & 66 & 83.5 \\
\cline { 2 - 6 } & Post-menopausal & 6 & 28.6 & 15 & 71.4 \\
\cline { 2 - 6 } & Present & 2 & 40.0 & 78 & 82.0 \\
\hline
\end{tabular}

Table 5: Mean CA-125 levels in Benign and Malignant Adnexal Masses $(n=100)$.

\begin{tabular}{|lllllll|}
\hline & & \multirow{2}{*}{ n } & Mean & \multicolumn{2}{l|}{ 95\% Confidence Interval for Mean } & p value \\
\hline \multirow{2}{*}{ CA-125 IU/ml } & Malignant & 19 & 257.30 & 105.68 & 408.92 & \\
\cline { 2 - 7 }$<0.001$ \\
\cline { 2 - 6 }
\end{tabular}

Table 6: Histopathological diagnosis in comparison with CA-125 when cut-off value of $35 \mathrm{ng} / \mathrm{ml}$ is $u$ sed ( $\mathrm{n}=100$ ).

\begin{tabular}{|c|c|c|c|c|c|}
\hline \multirow{2}{*}{ CA $125 \mathrm{IU} / \mathrm{ml}$} & \multicolumn{2}{|c|}{ Malignant (n = 19) } & \multicolumn{2}{|c|}{ Benign (n= 81) } & \multirow[b]{2}{*}{ p value } \\
\hline & $\mathbf{n}$ & $\%$ & $\mathbf{N}$ & $\%$ & \\
\hline Malignant & 18 & 94.7 & 10 & 12.3 & \multirow{2}{*}{$<0.001$} \\
\hline Benign & 1 & 5.3 & 71 & 87.7 & \\
\hline
\end{tabular}

Table 7: Performance of CA-125 in pre and post-menopausal age groups $(n=100)$.

\begin{tabular}{|llllll|}
\hline CA 125 (Inference) & Sensitivity & Specificity & PPV & NPV & Accuracy \\
\hline Pre-menopausal & $100.0 \%$ & $85.1 \%$ & $54.5 \%$ & $100.0 \%$ & $87.5 \%$ \\
\hline Post-menopausal & $85.7 \%$ & $100.0 \%$ & $100.0 \%$ & $93.3 \%$ & $95.2 \%$ \\
\hline Total & $94.7 \%$ & $87.65 \%$ & $64.28 \%$ & $98.6 \%$ & $88.91 \%$ \\
\hline
\end{tabular}

Most of the patients were married (76\%), premenopausal (79\%) and parous $(67 \%)$. A significant positive family history was reported by $5 \%$ of patients, although the exact diagnosis of other family members could not be ascertained in any one of them (Table 1). Pain was the most common complaint seen in $69 \%$ of the subjects followed by menstrual disturbances $(42 \%)$, lump in the abdomen $(23 \%)$, infertility $(5 \%)$ and postmenopausal bleeding (4\%) while as $6 \%$ were asymptomatic (Table 2).

Histopathologically 81 adnexal masses proved to be benign and 19 were diagnosed as malignant. Dermoid cyst $(25.9 \%)$, endometrioma $(21 \%)$ and serous cystadenoma $(18.5 \%)$ were the most common benign masses while as serous $(21 \%)$ and mucinous cystadeno-carcinoma (15.8\%) were the most common malignant masses (Table 3). The frequency of malignant masses was more in elderly, married, parous and post-menopausal groups (Table 4).
Mean CA-125 levels were significantly higher in malignant than in benign masses (257.30: 105.68-408.92 versus 19.26:16.53-22.00, $\mathrm{p}<0.001$ ) (table 5). CA-125 level was more than $35 \mathrm{IU} / \mathrm{mL}$ in 18 out of 19 malignant cases $(94.7 \%)$ with one false negative result. Only malignant case in which CA-125 was not elevated was mucinous cystadenocarcinoma. Among the benign cases, CA-125 was less than $35 \mathrm{IU} / \mathrm{ml}$ in 71 cases $(87.65 \%)$ whereas it was falsely elevated $(>35 \mathrm{IU} / \mathrm{ml})$ in 10 cases $(12.3 \%)$ and these were mostly endometriomas and tuboovarian abscesses (Table 6).

Sensitivity, specificity, positive predictive value, negative predictive value and accuracy of CA-125 for diagnosing malignant adnexal mass was 94.7\%, 87.65\%, 64.28\%, $98.6 \%$, and $88.91 \%$ respectively. When menopausal status was taken into consideration, sensitivity, specificity, positive predictive value, negative predictive value and accuracy was $100 \%, 85.1 \%, 54.5 \%, 100 \%, 87.3 \%$ in 
premenopausal women and $85.7 \%, 100 \%, 100 \%, 93.3 \%$, $95.2 \%$ in postmenopausal women respectively (Table 7).

\section{DISCUSSION}

More than 3/4th of patients diagnosed with adnexal masses at our center during the study period had a benign pathology. Higher frequency of malignant tumours was seen with increasing age of the patients. Parous and postmenopausal women also had higher frequency of malignant masses. This is consistent with the previous studies done in the Indian subcontinent as well as other parts of the world. ${ }^{7-10}$ Ovarian malignancies are thought to be related to ovulation and number of ovulatory cycles. ${ }^{11}$ Various theories like repeated epithelial trauma and repair related to ovulatory follicular rupture (the incessant ovulation theory) and persistent stimulation of ovaries by gonadotropins increasing epithelial proliferation (the gonadotropin theory) have been postulated about the mechanisms through which ovaries become more susceptible to cancer development. ${ }^{11}$

This study showed a high sensitivity, specificity and positive predictive value of CA-125 levels in diagnosing ovarian malignancies in postmenopausal women with adnexal masses. This is similar to the results shown in other studies and therefore warrants use of CA-125 routinely in such patients with aggressive search for malignant etiology in these patients. ${ }^{12-16}$ However, given higher incidence of malignant etiology and lower negative predictive value of CA-125 levels in post-menopausal women a thorough work up for malignant disease is mandatory even with normal CA-125 levels. ${ }^{12-16}$ A good sensitivity and negative predictive value of CA-125 in premenopausal women was seen in our study. This is also consistent with previous studies done so far. ${ }^{12-16}$ Normal CA-125 levels in premenopausal and younger women therefore almost rule out a malignant etiology.

Some studies have combined the use of serum CA-125 levels and doppler ultrasonography parametres (like mean pulsitality index and mean resistivity index) for evaluation of adnexal masses and ruling out malignant diseases. ${ }^{12-16}$ Individual investigations have also been compared with each other in many studies with most of the studies showing color doppler evaluation to be more specific in diagnosing malignancy as compared to the CA-125 levels. ${ }^{13,14}$ The combination of the two tests is also more specific than CA-125 levels. ${ }^{13,14}$ However the sensitivity of the combination of tests decreases significantly as compared to the use of CA-125 levels alone. ${ }^{13,14}$ The combination of tests may therefore be more relevant in young, premenopausal and nulliparous women where the prevalence of malignant diseases is less as compared to other groups.

\section{CONCLUSION}

Most of the adnexal masses across age groups have benign etiology. CA-125 levels have good sensitivity and specificity in differentiating between malignant and benign etiology in all age groups. However, CA-125 levels have higher positive and negative predictive value in post and premenopausal patients respectively which is due to the differences in the prevalence of malignant adnexal masses in the two age groups.

Funding: No funding sources

Conflict of interest: None declared

Ethical approval: The study was approved by the Institutional Ethics Committee

\section{REFERENCES}

1. ACOG; Practice Bulletin. Management of adnexal masses. Obstet Gynecol. 2007;110(1):201-14.

2. Drake J. Diagnosis and management of the adnexal mass. Am Fam Physician. 1998;57(10):2471-6.

3. Maggino T, Gadducci A, D'Addario V, Pecorelli S, Lissoni A, Stella $M$ et al. Prospective multi-centre study on CA-125 in postmenopausal pelvic masses. Gynecol Oncol. 1994;54:117-23.

4. MalkasianJr GD, Knapp RC, Lavin PT, ZurawskiJr VR, Podratz KC, Stanhope CR et al. Preoperative evaluation of serum CA-125 levels in premenopausal and postmenopausal patients with pelvic masses: discrimination of benign from malignant disease. Am J Obstet Gynecol. 1988;59:341-6.

5. Milojkovik M, Hrogovic Z, Hrgovic I, Jonat W, Maass N, Bukovic D. Significance of CA-125 serum level in discrimination between benign and malignant masses in the pelvis. Arch Gynecol Obstet. 2004;269:176-80.

6. Medeiros LR, Rosa DD, Rosa MI, Bozzetti MC. Accuracy of ultrasonography with color Doppler in ovarian tumours. Int $\mathrm{J}$ Gynaecol Cancer. 2009;19(2):230-6.

7. Jain KA. Prospective evaluation of adnexal masses with endovaginal gray-scale and duplex and color Doppler ultrasonography: correlation with pathological findings. Radiology. 1994;191(1):63-7.

8. Jha R, Karki S. Histological pattern of ovarian tumors and their age distribution. Nepal Med College J. 2008;10(2):81-5.

9. Luxman D, Bergamn A, Sagi J, David M. The postmenopausal adnexal mass: correlation between ultrasonic and pathologic findings. Obstet Gynecol. 1991;77:726.

10. Anuradha Khanna, Shweta Garg, RC Shukla, Mohan Kumar. Color Doppler study for differentiation of ovarian adnexal masses. Singapore J Obstet Gynecol. 2002;33(1):35-39.

11. Gharwan H, Bunch KP, Annunziata CM. The role of reproductive hormones in epithelialovarian carcinogenesis. Endocr Relat Cancer. 2015;22(6):R339-63

12. Banu S, Khatun S, Shamsuddin L. Assessment of adnexal masses by transvaginalsonography and serum CA-125 assay in the pre and postmenopausal women. Bangladesh J Obstet Gynecol. 2009;24(2):56-62. 
13. Alcazar JL, Errasti T, Zornoza A, Minguez JA, Galan MJ. Transvaginal color doppler ultrasonography, and CA-125 in suspicious adnexal masses. Int J Gynecol and Obstet Sept. 1999;66:255-261.

14. Erdogan N, Ozcelik B, Akgun M, Ozturk F. Doppler ultrasound assessment and CA-125 in the diagnosis of ovarian tumours. Int $\mathrm{J}$ Gynecol Obstet. 2005;91(2):146-50.

15. Mazhar SB, Jabeen K. Cross validation of Doppler ultrasound and gray scale imaging for discrimination of benign and malignant adnexal masses. JIMA. 2008;40:69-75.
16. Timor-Tritsch LE, Lerner JP, Monteagudo A, Santos R. Transvaginal ultrasonographic characterization of ovarian masses by means of color flow directed measurement and morphologic scoring system. Am J Obstet Gynecol. 1993;168:909.

Cite this article as: Khan SA, Rahi S, Khan N. Role of cancer antigen-125 in diagnosing malignant adnexal masses: a prospective observational study. Int J Reprod Contracept Obstet Gynecol 2020;9:4074-9. 